\title{
Chapter 6 \\ Project Redemption: Conducting Research with Informal Workers in New York City
}

\author{
Mallika Bose, Caprice Knapp, Margaret S. Winchester, Agustina Besada, \\ and Amelia Browning
}

\subsection{Introduction and Background}

In every country there are workers who perform jobs every day that many citizens do not want to perform. Housekeepers, garbage collectors, and manual laborers are examples of some of these jobs and oftentimes they are done as informal work, meaning they are not part of the formal labor market. In some countries these jobs are done by immigrants or others, such as people with addictions, mental illness, or felons, or those who otherwise find themselves unable to enter the formal labor market (Medina 2008). The establishment of the informal sector provides individuals unable to obtain other forms of formal employment with a way to make a living, which serves as a means to informally reduce unemployment (Afon 2007). Regardless of who is engaged in informal work, these positions are vital to the economy and are typically undervalued and overlooked (Scheinberg and Anschtz 2006).

Informal workers are not typically covered under federal or state legislation protecting worker's rights. Some sub-groups of informal workers, such as manual laborers in the United States and Mexico have formed their own organizations that support their needs as informal workers (Sarmiento et al. 2016). The creation of such groups for U.S. manual day workers (e.g. informal construction workers) arose from the worker's similar cultural and migration identities, and eventually the

\footnotetext{
M. Bose $(\bowtie)$

Department of Landscape Architecture, Pennsylvania State University,

University Park, PA, USA

e-mail: mub13@psu.edu

C. Knapp · M. S. Winchester · A. Browning

Department of Health Policy and Administration, Pennsylvania State University, University Park, PA, USA
}
A. Besada
Sure We Can, Brooklyn, NY, USA 
workers' self-organization garnered support from local communities and organizations (Sarmiento et al. 2016). Informal workers, however, are not unaffected by laws and regulations. For instance, informal workers known as wastepickers can capitalize on state laws in the U.S. that pay people to recycle cans and bottles. For the U.S. wastepicker, laws like the Bottle Bill have aided in the development of the informal sector.

In the case of 'wastepickers', these workers are also important for the environment and contribute to sustainability. Wastepickers, otherwise known as trashpickers, ragpickers, informal recyclers, canners, or scavengers, are people who collect recyclable materials and redeem these for money. In the 1970s, environmental interest groups in the U.S. lobbied for the passage of a federal redemption law, which would have provided monetary incentives for people to collect bottles and cans all over the country (Fiske 1983). The federal legislation did not pass, but over a little more than a decade ago, ten states and Guam passed similar redemption laws (Fiske 1983; BottleBill.org 2016). The purpose of redemption legislation was to provide people with an incentive to act in an environment-friendly way, and while redemption laws have had the intended effect, they also serve as a form of selfemployment and economic opportunity for some people. In 2002, Hawaii became the 10th state to enact a redemption law (BottleBill.org 2015).

In India, there are formal and informal wastepickers. Formal wastepickers, such as those in Pune, work with the government as part of the city's recycling program (Chikarmane and Narayan 2000). Pune wastepickers collect all types of potentially recyclable waste from households, sort the waste at designated stations, and the waste is then recycled by the city. Wastepickers in Pune are paid for their duties and they have an organized union. In Nicaragua wastepickers live in landfills (Hartmann 2013). These wastepickers wait until the waste is collected and dumped at the site and then they scavenge through the waste for materials that can be recycled for money. Although the wastepicking may not be legal, cities allow the wastepickers to perform this task and even live on site. Ghana's Agbogbloshie is a large dump site for electronic waste. Wastepickers at that site collect the electronic material that has been dumped, such as laptops and cell phones, and harvest materials such as copper that can be found in cords and other metals and redeem these for money (Otsuka et al. 2012). Certainly the definition of wastepicker varies by country in terms of what is being collected and if these are formal or informal workers; but the fundamental concept of collecting materials that can be recycled and redeeming them for money is common around the world.

There are also various definitions of vulnerable populations, all of which apply to wastepickers. Vulnerable populations are a disadvantaged subgroup of society (Aday 1994). This is certainly true of wastepickers as they do not have the advantages of the formal labor market and they are from low socioeconomic conditions which in and of itself is a vulnerability. Many wastepickers have few years of education, which prevents them from entering the workforce or obtaining jobs with higher skill levels. While wastepicking provides an income, it often does not include employment benefits, and in some cases the recycling industry may take advantage of wastepickers (Auler et al. 2014). Likewise, wastepickers bear the risk of inclement weather, harassment from authorities and other citizens, and potential injuries 
from scavenging. A study of Nigerian wastepickers found that wastepickers were susceptible to injury and disease from rodents and insects that lived in poorly stored waste (Afon 2007). Broken glass and other potentially harmful materials also pose a threat to wastepickers sorting through trash to find redeemable cans or bottles. Adverse weather conditions, disease, and injury may also hinder or prevent a wastepicker from collecting bottles or cans. Since a wastepicker's income depends on his or her ability to collect recyclable waste, these occupational vulnerabilities threaten a wastepicker's livelihood.

Wastepickers have few resources to mitigate these risks. By not participating in the formal labor market they do not enjoy the protections afforded by labor laws, and may not have all the information needed to make informed choices. These vulnerabilities can be exacerbated if wastepickers live in informal housing, lack sanitation systems, or experience food insecurity. Vulnerabilities are also increased if wastepickers are immigrants, particularly those without legal permission to be in a country, as they are performing a valuable service for that society but have limited legal protection in the society. Fear of deportation also adds to vulnerability. All these factors make wastepickers an economically and socially vulnerable subgroup in a society (Auler et al. 2014). Vulnerable groups need special attention if their situation is to be improved, meaning their needs must be understood and their challenges should demand solutions. More importantly, vulnerable groups like wastepickers deliver a useful service and there needs to be a recognition of their contribution to society. In order to gain an understanding of the multi-dimensionality of the lives of groups like wastepickers, we need to comprehend the different facets of their lives and livelihood from their point of view. In doing so, we also need to be mindful of ethical considerations regarding research with vulnerable groups.

Motivation Our study team wanted to learn about the health of wastepickers in the United States. This group is of particular interest due to their vulnerability, the existence of laws for redeeming recycling which provides income, and even though this group has rarely been studied they are important in the economic and environmental services they provide. New York is one of the states that has a redemption law otherwise known as the Bottle Bill (Levitt and Leventhal 1986). A five cent deposit is included in the price of most beverage containers sold to final consumers by a retailer. Consumers or anyone with an empty beverage container may return the empty container to retailers, redemption machines, or redemption centers and get back the five cents. Although there are a variety of redemption centers in New York City, only one is a non-profit. This non-profit redemption center, called Sure We Can (SWC), is committed to community improvements in Brooklyn and environmental sustainability. As a result, this center provides an excellent opportunity to study the health of wastepickers, locally called canners, using a community based participatory framework.

Community-based participatory research (CBPR) is an approach to research that is grounded in collaborative equitable partnerships through the entire research process (Minkler and Wallerstein 2011). It is an asset-based approach to research (Green and Haines 2015) which recognizes and acknowledges the resources and 
strengths available in a community and leverages these assets for positive change. Since it is change oriented, CBPR seeks to balance research needs with positive action for its partners. Furthermore, we conceived and implemented this CBPR project with an interdisciplinary group of researchers which allowed us to holistically consider the issue of health and healthcare utilization of canners in NYC.

\subsection{Process}

The participatory process followed by Pennsylvania State University (PSU) researchers and SWC unfolded over several months in 2016 and 2017. On our first visit to SWC in March 2016, we met with Ana De Luco, one of the co-founders of Sure We Can, the only non-profit can redemption center in the New York City area. The PSU researchers wanted to connect with SWC and express interest in working with canners in New York City. Fortunately, Ana was interested in exploring how we could develop a project to examine the health utilization of canners of SWC. Ana was motivated because, even though SWC had partnered with several higher education institutions and nonprofits, they did not at that moment have any initiatives focused on health. She was looking for opportunities to find out more about the health care needs of the canners that used the services of SWC and she hoped that our project would fulfill this need. Thus, began our interdisciplinary collaboration with SWC. In addition to having an interdisciplinary group of researchers from PSU partnering with SWC, we involved graduate and undergraduate students in several stages of the project.

This underscores the fact, that for any fruitful participatory process, all parties require their needs to be satisfied. The PSU researchers wanted to understand the health status and the healthcare needs of canners in NYC, while SWC wanted to find out more about the health needs of its community so that they could provide better services to the canners that used their facility. The PSU researchers also wanted to use this project to offer research opportunities to Penn State students and expose them to community based research.

\section{Community Partner: Sure We Can}

- SWC is a non-profit recycling center, community space and sustainability hub in Brooklyn, New York where canners, who are people that collect cans and bottles from streets to make a living, come together with students and neighbors through recycling, composting, gardening and arts.

- Their mission is to support the local community, particularly the most vulnerable residents, and promote social inclusion, environmental awareness and economic empowerment. For over 9 years, Sure We Can has served the community of canners, and today it has evolved into a community center that promotes a sustainable urban culture and facilitates a circular economy.

- More than 500 canners are part of their community, collecting over ten million cans and bottles last year (2016) alone. 
The majority of the wastepickers in our proposed study population were immigrants. Migration, and the health of migrants, are an important component of global health. As we described our study to our PINGH colleagues we learned about our partners who had worked with informal workers. We wanted to learn from our partners in Pune, India at the Savitribai Phule Pune University (SPPU), who have a long-standing relationship with a wastepicker organization in the city (Kagad Kach Patra Kashtakari Panchayat - KKPKP). The wastepickers in Pune are organized, have a long history and work with the municipality to collect and process household waste. Even though the Pune waste pickers collect a wider range of products we wanted to learn from the experience of an organized group of waste-pickers. However, the timing of activities between the PSU team and the SPPU team and the geographical distance proved to be very challenging. We were unable to complete a multi-sited project between the two groups, but will leverage our findings and lessons from the US to develop the next phases of research targeting both sites. We plan to collect additional data in India and Ghana, through PINGH partners.

Collaborative and equitable partnership From the onset, SWC stressed that this project needed to be a collaborative partnership. Since Ana was in the process of handing over the reins of SWC to Agustina Besada - who was taking over as the Executive Director of SWC - Ana introduced us to Agustina who then served as the main contact for SWC for the project. We first met with Agustina in August 2016, and between August 2016 and March 2017 - the PSU research team met with Agustina and SWC representatives regularly to establish a working relationship and to develop the research process/protocol for the study. This collaborative process was crucial for the development of trust between the research team and SWC. It also led to the development of a feasible study protocol that would be useful for all involved partners. Agustina was involved in all stages of the research process. We had several discussions regarding the research questions driving the study and the methodology to be followed. We collectively made decisions regarding questions to include in the survey and semi-structured questionnaire and the particulars of the methods to be used. For example, initially, the research team was interested in piloting the use of GPS devices to understand the routes taken by individual canners. However, Agustina was not sure of using GPS trackers and thought that some canners would be distrustful of such a method and it might compromise the entire research study. So ultimately, instead of using GPS trackers, we decided to use a map of the SWC neighborhood to solicit information about their canning route. Canners described the route that they took most frequently and any important landmarks along this path.

Mutually helpful process Even though the research team's main interest was in understanding the healthcare status of canners, how they accessed health care services, and what could be done to improve healthcare utilization of this vulnerable group; the research protocol included questions that were of importance to SWC. The survey included a section on the experience that the canners had with Sure We Can services. The results of this section of the survey will assist SWC in improving the services that they provide to the canning community. Similarly, the 




Fig. 6.1 Health information card with basic biometric measures was filled out and given to each participant taking part in the survey (front and back)

qualitative interview included questions about SWC and how the organization helped them and could improve the services that they provided to the canners. We were also committed to provide the study participants with something of utility - so that they would gain something immediately from the project beyond helping us understand their healthcare status and healthcare utilization patterns. After the survey we provided the participants with some basic information regarding their health status in the form of a health card that we handed back to them (see Fig. 6.1). Participants could use this to self-monitor any conditions, or use it as a reference point when visiting a health provider.

Asset-based Approach In developing the questions for the survey and the qualitative interviews, we were careful to not focus solely on deficiencies or unmet needs of the canners (Green and Haines 2015). Accordingly, the survey probed into the different dimensions of canning, including how the activity of canning and SWC positively impacted their lives. In the same vein, the qualitative questions asked the canners about the benefits of canning to the individual canners as well as the community. This was predicated on the belief that canning is a sustainable, useful income-generating activity and not necessarily an act of last resort. This was corroborated by the individual stories of canners: for example, one of the canners picked up cans for fun and exercise. He had a regular job, but engaged in canning for an hour or two every day to give him an excuse to walk around the city and to talk to people who he would otherwise not talk to in the process of his daily activities.

Interdisciplinary Approach This study was shaped from the very beginning by an interdisciplinary approach. The PSU researchers represented various disciplinary (and professional) backgrounds: medical anthropology, health economics, and urban planning. Consequently, the study was conceptualized holistically - we wanted to look at canning as a productive activity that was both sustainable and at the same time linked to possible health hazards and exploitation. This also had implication for the research questions driving the study and the methodology used. The urban planner was interested in the spatial aspects of the canners lives - the 
routes that they took, and how the routes were related to their health utilization behavior. The anthropologist was keen to collect the stories of the canners - in their own voices, while the health economist wanted to find out about the health status of canners at SWC and the different dimensions of health care access and utilization. Accordingly, we used a mixed methods approach blending surveys with qualitative interviews that included mapping.

\subsection{Challenges and Lessons Learned}

The outcome of this extended collaboration building and data collection was a small but well-rounded mixed methods pilot study. We were able to identify key health issues and barriers among canners using the facilities at SWC. With the research team, students conducted brief health assessments, surveys, and qualitative interviews with 15 canners at Sure We Can.

One practice that we built into the process was the inclusion of students into all phases of research. Students seeking research experience assisted with the IRB submission, survey and qualitative interview design, data collection, and data analysis. One undergraduate student served as the research assistant (RA) for the project and was involved in all phases of the project. All of the students doing data collection had language skills to match the population of SWC canners, including English, Spanish, Mandarin, and Cantonese. They went through a half day training process on qualitative interviewing, conducted by professionals from the Center for Health Care and Policy Research at Pennsylvania State University. Rather than act as translators, students were able to speak directly with canners and remove a potential barrier to communication, while gaining valuable skills and experience. Further, a graduate student in Health Policy and Administration analyzed the study data to complete her master's thesis.

For the student RA, this was the first project in which she had the opportunity to engage in all aspects of research: from developing the research questions, getting IRB approval, recruitment, training, fieldwork/data collection, data analysis and writing. Her other research experiences involved working on data analysis and lab work, so this project served as her introduction to community based participatory research. She enjoyed this experience, and is looking to combine community-based research with her interest in photography and filmmaking as she thinks of her career path. When asked to comment on what had perhaps not worked so well and needed to be approached differently, she mentioned that she would have enjoyed a more active mentorship model, especially since as an undergraduate student this was a novel experience for her. This is a reminder for faculty to make time for their students and think intentionally of their role as mentors responsible for training the next generation of research practitioners. Another point the RA made was the need for more training in the methods of research in a cross-cultural context. Even though we trained students in undertaking survey and interview research under a community based research framework, we could have done a better job in developing 
cross-cultural competency. This would have probably helped the students in their interview/survey process and eased some of their anxiety. This is also a reminder of the sophistication of undergraduate student researchers and points to the need for faculty to involve undergraduate students in community based research practices, especially as it may shape their career trajectories. In a similar fashion, another undergraduate student characterized this experience as "unlike any other experience in college". He enjoyed the opportunity to work alongside a community (canners) about which relatively little is known.

The iterative and longitudinal process of developing a community partnership between faculty at PSU and colleagues at SWC has created a strong foundation. Our initial data collection has highlighted potential points of intervention and further study with canners, while solidifying the partners' desire to continue working together. We plan to replicate some parts of our study in other sites, while maintaining flexibility to understand informal workers in diverse contexts. Of particular note has been the successful inclusion of students across phases of the research process and emphasis on community assets. This model can assist others in developing community partnerships and working with vulnerable populations.

\section{Challenges}

- We faced challenges coordinating data collection across sites, and focused on one area for a pilot study.

- Truly engaged methodology is challenging with a vulnerable research population, due to language and accessibility.

\section{Lessons Learned}

- Using a nonprofit partner helps with managing issues of access, engagement, and relevance of research.

- Student involvement at all stages of the research process helps with training future researchers and minimizing the barriers of using translators during interviews.

Acknowledgements The authors thank the canners in the study, first and foremost, for sharing their time and experience with us. We also thank Sure We Can for their partnership, accommodation, and the important work they are doing. Additionally, the following Pennsylvania State University students were invaluable to the research process: Sarah Kidder, Tiange Chen, Tim Groh, Julian Orozco, Jingnan Miso, and Tianzhou Shen.

\section{References}

Aday LA (1994) Health status of vulnerable populations. Annu Rev Public Health 15(1):487-509. https://doi.org/10.1146/annurev.pu.15.050194.002415

Afon AO (2007) Informal sector initiative in the primary sub-system of urban solid waste management in Lagos, Nigeria. Habitat Int 31(2):193-204. doi.org/10.1016/j.habitatint.2007.02.007 
Auler F, Nakashima ATA, Cuman RKN (2014) Health conditions of recyclable waste pickers. J Community Health 39:17-22. doi.org/10.1007/s10900-013-9734-5

BottleBill.org (2015) Bottle Bills in the USA: All US Bottle Bills. http://www.bottlebill.org/legislation/usa/allstates.htm. Accessed 25 Oct 2017

BottleBill.org (2016) Bottle Bills in the USA: New York. http://www.bottlebill.org/legislation/usa/ newyork.htm. Accessed 25 Oct 2017

Chikarmane P, Narayan L (2000) Formalising livelihood: case of wastepickers in Pune. Econ Polit Wkly 35(41):3639-3642

Fiske CH (1983) The return to returnables: New York enacts a bottle bill. Pace Law Rev 4:141-167

Green GP, Haines A (2015) Asset building \& community development. Sage Publications, Los Angeles

Hartmann CD (2013) Garbage, health, and well-being in Managua. NACLA Rep Am 46(4):62-65

Levitt L, Leventhal G (1986) Litter reduction: how effective is the New York State bottle bill? Environ Behav 18(4):467-479. doi.org/10.1177/0013916586184003

Medina M (2008) The informal recycling sector in developing countries: organizing waste pickers to enhance their impact. Gridlines; No. 44. World Bank, Washington, DC. https://openknowledge.worldbank.org/handle/10986/10586

Minkler M, Wallerstein N (eds) (2011) Community-based participatory research for health: from process to outcomes. Wiley, Hoboken

Otsuka M, Itai T, Asante KA et al (2012) Trace element contamination around the e-waste recycling site at Agbogbloshie, Accra City, Ghana. Interdiscip Stud Environ Chem Environ Pollut Ecotoxicol 6(6):161-167

Sarmiento H, Tilly C, de la Garza Toledo E, Gayosso Ramirez JL (2016) The unexpected power of informal workers in the public square: a comparison of Mexican and US organizing models. Int Labor Work Class Hist 89:131-152. doi.org/10.1017/S0147547915000368

Scheinberg A, Anschtz J (2006) Slim pickin's: supporting waste pickers in the ecological modernization of urban waste management systems. IJTMSD 5(3):257-270. doi.org/10.1386/ ijtm.5.3.257/1

Open Access This chapter is licensed under the terms of the Creative Commons Attribution 4.0 International License (http://creativecommons.org/licenses/by/4.0/), which permits use, sharing, adaptation, distribution and reproduction in any medium or format, as long as you give appropriate credit to the original author(s) and the source, provide a link to the Creative Commons license and indicate if changes were made.

The images or other third party material in this chapter are included in the chapter's Creative Commons license, unless indicated otherwise in a credit line to the material. If material is not included in the chapter's Creative Commons license and your intended use is not permitted by statutory regulation or exceeds the permitted use, you will need to obtain permission directly from the copyright holder.



